\title{
Using Density Functional Theory to Study Shape-Reactivity Relationships in Keggin Al- Nanoclusters
}

\author{
Katie W. Corum ${ }^{\mathrm{a}}$ and Sara E. Mason ${ }^{\mathrm{a} *}$ \\ ${ }^{\mathrm{a}}$ Department of Chemistry, University of Iowa, Iowa City, IA 52242 \\ *Corresponding author: Sara-mason@uiowa.edu
}

Abstract

Keggin-based aluminum nanoclusters have been shown to be efficient sorbents for the removal of arsenic from water. Obtaining a molecular-level understanding of the adsorption processes associated with these molecules is of fundamental importance, and could pave the way for rational design strategies for water treatment. Due to their size and the availability of experimental crystal structures, Al nanoclusters are computationally tractable at the density functional theory (DFT) level. Here, we compare the reactivity of three aluminum polycations:

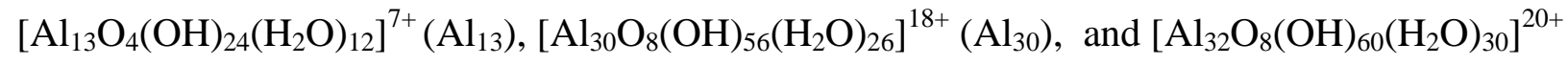
$\left(\mathrm{Al}_{32}\right)$. We use DFT calculations to determine reactivity as a function of particle topography, using sulfate and chloride as adsorption probes. Our comparative modeling of outer-sphere adsorption of $\mathrm{Cl}^{-}$and $\mathrm{SO}_{4}{ }^{2-}$ on $\mathrm{Al}_{13}, \mathrm{Al}_{30}$, and $\mathrm{Al}_{32}$ supports that the unique "hourglass" shape characteristic to $\mathrm{Al}_{30}$ gives rise to relatively strong adsorption in the molecular beltway, as well as a wide range of reaction energies as a function of particle topography. The DFT trends in outer-sphere adsorption energy stated in this paper suggest that the apparent shape-reactivity relationship supersedes reactivity predictions based on oxygen functional group type alone.

Keywords: Al Keggins; Al polycations; $\mathrm{DFT} ; \mathrm{Al}_{30}$; reactivity; adsorption 
Introduction

Al-based materials are known to exhibit high reactivity towards polyoxoanion species such as arsenate, and therefore are frequently used in coagulation-coprecipitation and adsorptionbased water remediation. Studies point to the utility of the Keggin-based aluminum hydroxide nanocluster $\left[\mathrm{Al}_{30} \mathrm{O}_{8}(\mathrm{OH})_{56}\left(\mathrm{H}_{2} \mathrm{O}\right)_{26}\right]^{18+}\left(\mathrm{Al}_{30}\right)$ in the efficient removal of arsenic from water. Mertens et al. have been prime investigators in researching the removal of inorganic sodium arsenate from contaminated water samples. (Mertens et al., 2012a) In a recent study, the reactivity of several Al-based sorbents was compared by measuring the uptake capacity of arsenic, specifically As(V).(Mertens et al., 2016) The materials tested included $\mathrm{Al}_{30}$ solution, $\mathrm{Al}_{30}$ enriched polyaluminuym chloride $\left(\mathrm{PACl}_{30}\right)$, polyaluminum granulate ( $\left.\mathrm{PAG}\right)$, and the natural $\mathrm{Al}$ mineral phase, gibbsite. The pure $\mathrm{Al}_{30}$ and $\mathrm{PACl}_{30}$ showed similar As uptake efficiency, suggesting that the $\mathrm{Al}_{30}$ content of $\mathrm{PACl}_{30}$ is responsible for its reactivity towards the contaminant. All of the nanocluster sorbents adsorbed at least $93 \%$ of arsenic from solutions of initial arsenic concentration ranging from $0.133-0.667 \mathrm{mmol} / \mathrm{L}$, while the gibbsite sample only decreased the $\mathrm{As}(\mathrm{V})$ concentration by $50 \%$. While $\mathrm{Al}$ nanoclusters can adsorb contaminants at a variety of $\mathrm{pH}$ conditions it has been shown that $\mathrm{PACl}_{30}$ efficiency is highest near neutral $\mathrm{pH}$, making it an excellent candidate for the purification of natural waters.(Mertens et al., 2012a, Mertens, 2011, Mertens et al., 2012b)

Conceptually, the high reactivity of the $\mathrm{Al}_{30}$ molecule has been rationalized through structure-reactivity relationships that were developed for extended mineral surfaces and based on Pauling's rules of inorganic crystal stability.(Pauling, 1929) Mineral-water interfaces are welldefined models for geochemical systems. Surface energetics for mineral-water interfaces have been extracted experimentally, but it is time consuming and relative to UHV conditions. (Israelachvili and Adams, 1978, Jordan and Geiger, 2014) Theoretical studies using methods 
47 such as DFT and ab initio molecular dynamics (AIMD) can help to fill in the conceptual gap

48 between macroscopic experiments and molecular understanding. However, information from

49 atomistic modeling currently trails the information obtained from over a decade of experimental

50 studies of hydrated single-crystal surfaces (see, for example, Catalano et al. (2008), Fenter et al.

51 (2000), Fenter and Sturchio (2004), Eng et al. (2000), Catalano (2010), Rosso et al. (2010),

52 Abadia et al. (2014)). In the absence of more robust chemical modeling, bond-valence theory

53 has been a popular and useful means of mapping experimental information about adsorption to

54 structure-property relationships. The bond-valence model as formulated by Brown relates bond

55 length to bond strength through the bond valence $s$ of atom type $i$.(Brown, 2009) The model is

56 parametrized such that the sum over $s_{i}$ for each atom should equal its formal valence, where

$57 s_{i}=\left(\mathrm{R} / \mathrm{R}_{0}\right)^{-\mathrm{N}}, \mathrm{R}$ is the observed bond length while $\mathrm{R}_{0}$ and $\mathrm{N}$ are fitted bond valence parameters.

58 The conceptual result born out of bond-valence theory is that functional group type is a key

59 predictor of mineral surface reactivity.(Hiemstra et al., 1989) In a recent review, Brown and

60 Calas (2011) discuss the oxygen functional groups exposed as "long-term docking stations".

61 They explain that the formation of (partially covalent) inner-sphere (IS) adsorption complexes

62 immobilizes the adsorbate. On the other hand, outer-sphere (OS) adsorption is considered to be

63 relatively weak on mineral-water interfaces. Here, when were refer to an OS adsorption complex

64 involving an Al Keggin molecule, we specifically mean that no ligand exchange occurs between

65 the $\mathrm{Al}$ atoms of the Keggin and the adsorbate. Conventionally, the interaction between the

66 adsorbate and the Keggin would be thought to be weaker in an OS complex than in an IS

67 complex.

68 It is easy to see why, in conjunction with high reactivity noted in the literature, the

69 importance of functional group number and type is assumed to govern the reactivity of Al 
nanoclusters. The $\mathrm{Al}_{13}$ molecule has two types of exposed doubly bridging ligands $\left(\mu_{2}-\mathrm{OH}\right)$ and

71 twelve equivalent bound water molecules $\left(\eta-\mathrm{H}_{2} \mathrm{O}\right) . \mathrm{Al}_{30}$ and $\mathrm{Al}_{32}$ are comprised of two $\delta-\mathrm{Al}_{13}$

72 Keggin units, $\left[\mathrm{Al}_{13} \mathrm{O}_{4}(\mathrm{OH})_{24}\left(\mathrm{H}_{2} \mathrm{O}\right)_{12}\right]^{7+}\left(\mathrm{Al}_{13}\right)$ connected by four $\mathrm{Al}$ linkers.(Abeysinghe et al.,

$732012,2013 a)$ There are three surface functional group categories in the $\mathrm{Al}_{30}$ and $\mathrm{Al}_{32}$ molecule -

74 bound water molecules $\left(\eta-\mathrm{H}_{2} \mathrm{O}\right)$, doubly bridging ligands $\left(\mu_{2}-\mathrm{OH}\right)$, and triply-bridging ligands

$75\left(\mu_{3}-\mathrm{OH}\right) .\left(\mathrm{Rustad}, 2005\right.$, Casey, 2006, Casey and Rustad, 2007, Sun et al., 2011) The $\mathrm{Al}_{32}$

76 molecule contains two additional $\mathrm{Al}$ atoms on the $\mathrm{Al}_{30}$ molecule but contains the same types of

77 oxygen functional groups. Indeed, the existence of numerous distinct functional groups on the

78 surface of the Al Keggin molecules has been highlighted as an argument for adopting these

79 species as geochemical models.(Casey and Rustad, 2007, Casey, 2006)

The Keggin structural motif common to the Al nanoclusters studied here is of

81 general interest to a wide range of chemistry beyond adsorption. For example, Furrer et al

82 has studied aluminum flocs and have found that the Al flocculants that precipitate from

83 streams contain a significant amount of $\mathrm{Al}(\mathrm{O})_{4}$, which is the building blocks of the $\varepsilon-\mathrm{Al}_{13}$

84 Keggin.(Furrer et al., 2002) The ferrihydrite structure of Michel et al. based on pair distribution function analysis exhibits similarities to the $\delta$-Keggin structure.(Michel et al., 2010) More recently, an $\alpha$-Keggin $\mathrm{Fe}_{13}$ cluster was characterized by Sadeghi et al.,

87 providing further evidence that the growth of both natural and synthetic phases proceeds

88 by aggregation of clusters.(Sadeghi et al., 2015) The Keggin motif in prenucleation

89 clusters has also been observed in Nb-polyoxometalate systems.(Hou et al., 2013) Other aspects of the reactivity of Keggin clusters have been shown to depend on composition. For

91 example, Rustad and Casey have determined heteroatom substitution can impact the kinetics of

92 ligand exchange reactions.(Rustad and Casey, 2012, Rustad et al., 2004, Reusser et al., 2014) 
These examples of broad interest in Keggin clusters provides further motivation for

94 modeling studies aimed at assigning their reactivity to underlying physical properties.

In our previous work, we carried out DFT calculations to rationalize the crystal structure

96 of an $\mathrm{Al}_{30}$ Keggin species with two surface-bound $\mathrm{Cu}^{2+}$, referred to as $\mathrm{Cu}_{2} \mathrm{Al}_{30}-\mathrm{S}$. (Abeysinghe et

97 al., 2013b) The crystallization was done in the presence of disulfonate ions (2,6-NDS), and the

98 structure exhibited $\mathrm{Cu}^{2+}$ bound to $\mathrm{Al}_{30}$ in a corner-sharing bidentate fashion, while the sulfonate

99 groups had an OS relationship to the molecule. DFT modeling of IS $\mathrm{Cu}^{2+}$ adsorption and/or OS

$100 \mathrm{SO}_{4}{ }^{2-}$ adsorption (as a simplified approximation to the bulky 2,6-NDS counter ions used in the

101 experiment) was carried out. When $\mathrm{Cu}^{2+}$ and $\mathrm{SO}_{4}{ }^{2-}$ adsorption was considered separately, the

102 cation and anion showed opposite trends in adsorption site preference as a function of location

103 on the particle surface. Specifically, $\mathrm{Cu}^{2+}$ adsorption was preferred at the ends or "caps" of the

104 molecule, while $\mathrm{SO}_{4}{ }^{2-}$ adsorption was preferred in the molecular center or "beltway" region.

105 Furthermore, while OSadsorption is generally thought of as a weak interaction, the reaction

106 energies associated with the $\mathrm{OS}$ adsorption of $\mathrm{SO}_{4}{ }^{2-}$ were relatively large. When co-adsorption

107 was modeled, the preferred structure had both $\mathrm{Cu}^{2+}$ and $\mathrm{SO}_{4}{ }^{2-}$ adsorbed in the beltway, congruent

108 with the crystal structure and suggested that the strong OS adsorption controlled the coadsorption

109 site preference. The variation in the $\mathrm{Cu}^{2+}$ and $\mathrm{SO}_{4}{ }^{2-}$ adsorption energies as a function of

110 molecular topography, specifically between the beltway and caps, was greater than $1 \mathrm{eV}$ per ion,

111 despite the fact that all of the inner-sphere adsorption geometries involved two $\eta-\mathrm{H}_{2} \mathrm{O}$ groups.

112 These results suggest that reactivity factors other than oxygen functional group identity were

113 governing the DFT energy trends. Plots of the electrostatic potential $\left(V_{\mathrm{el}}\right)$ mapped onto the

114 charge density of the molecule revealed that the unique "hourglass" shape of $\mathrm{Al}_{30}$ gives rise to

115 more positive values in the beltway and less positive values at the caps. The reason for this 
116 variation is attributed to how the topography of the particle surface affects the distribution of $\eta$ -

$117 \mathrm{H}_{2} \mathrm{O}$ functional groups. In the former, $\mathrm{SO}_{4}{ }^{2-}$ can only interact with the oxygen functional groups

118 directly beneath it, while in the latter the $\mathrm{SO}_{4}{ }^{2-}$ can interact with a larger area of the $\mathrm{Al}_{30}$ surface.

119 In the present work, we aim to directly assess how shape affects adsorption trends on

$120 \mathrm{Al}_{13}, \mathrm{Al}_{30}$, and $\mathrm{Al}_{32}$, using DFT calculations and AIMD. We model OS adsorption of $\mathrm{SO}_{4}{ }^{2-}$ and

$121 \mathrm{Cl}^{-}$to sample the potential energy surfaces of the three $\mathrm{Al}$ nanoclusters. $\mathrm{SO}_{4}{ }^{2-}$ and $\mathrm{Cl}^{-}$are chosen

122 as representative probe adsorbates based on their common use in crystallization experiments.

123 Additionally, these ions allow us to compare reactivity trends as a function of adsorbate size and

124 charge, and can be considered an analog for contaminant polyoxoanions such as selenate and

125 molybdate. These different ions all have a different ionic radii and this could lead to a more

126 complete discussion of how the size of the ion effects reactivity.

127 Computational and Theoretical Methods

128 AIMD simulations and DFT geometry optimizations are carried out using the DMol ${ }^{3}$ 129 package developed by Delley,(Delley, 1990, 2000) with aqueous effects accounted for by the 130 conductor-like screening model (COSMO).(Klamt and Schüürmann, 1993) The AIMD 131 trajectories are used to search for minimum energy adsorption configurations, which allows for a 132 better sampling of the potential energy surface than through static DFT calculations alone. 133 AIMD simulations were carried out in the $(N, V, T)$ ensemble with trajectories of 1000 steps of 1340.463 fs. The temperature was set at $330+/-2 \mathrm{~K}$ and controlled by using the Nosé-Hoover chain 135 (NHC)(Nose, 1984, Hoover, 1985) method. A temperature higher than normal environmental 136 conditions was intentionally chosen to give the system additional thermal energy such that more 137 of the potential energy surface would be accessible to the adsorbate. The lowest energy 138 configurations from the AIMD simluations were then subjected to geometry optimization at the 
139 DFT level, and all of the reported energetics in this study are from those DFT results. An 140 additional reason to consider higher temperature in a system with many bound water groups is 141 the fact that the GGA style exchange correlation functional used in our calcuylations has been 142 shown to over-structure water.(Leung et al., 2006) The inversion symmetry of $\mathrm{Al}_{30}$ and $\mathrm{Al}_{32}$ is 143 maintained in the adsorbed systems by modeling two anions with atomic coordinates that are 144 also related by inverstion symmetry.

145 Select configurations of $\mathrm{SO}_{4}{ }^{2-}$ and $\mathrm{Cl}^{-}$adsorption at distinct positions (in terms of 146 molecular topography) were then subjected to DFT geometry optimization. The geometry 147 optimization calculations were carried out at the GGA-PBE (Perdew et al., 1996) level with a 148 structural convergence criterion of $0.03 \mathrm{eV} / \AA$ A. A DNP numerical atom-centered basis set (with a 149 cutoff radius of $3.5 \AA$ ) was used to expand the single electron orbitals. Further details of the 150 computational optimization methods (including prior benchmarking and convergence studies) 151 are reported in our previous work.(Abeysinghe et al., 2013b, Corum and Mason, 2015, Fairley et 152 al., 2015)

153 In order to use probe adsorbates to sample the potential energy surface of the $\mathrm{Al}$ 154 nanoclusters, it is necessary to model the isolated molecular form. Molecular Al nanocluster 155 geometries are generated based on the experimental crystal structures of $\mathrm{Al}_{13},\left(\mathrm{~J}_{\mathrm{ohansson}}, 1960\right)$ $156 \mathrm{Al}_{30}$,(Abeysinghe et al., 2012) and $\mathrm{Al}_{32}$. (Abeysinghe et al., 2013a) Protonation states of the 157 exposed oxygen functional groups are determined based on a bond-valence analysis. The 158 molecular structures are then embedded in the COSMO continuum solvent model (with a 159 dielectric constant of 78.54 to simulate water), and fully optimized at the DFT level. The 160 average bond distances between the tetrahedral $\mathrm{Al}$ and the four bound $\mathrm{O}$ atoms for all three 161 aluminum nanoparticles are tabulated and compared to the experimental structure in Table 1, 
162 showing excellent structural agreement between the modeled molecular structure and the experimental crystal structure.

Two adsorption configurations (for each adsorbate) were fully optimized for $\mathrm{Al}_{13}$ and $165 \mathrm{Al}_{30}$, and three configurations were fully optimized for $\mathrm{Al}_{32}$. The initial adsorption configurations 166 for all three molecules are shown schematically in Figure 1. The two adsorption configurations 167 for $\mathrm{Al}_{13}$ are labeled $\mathrm{A}_{13}$ and $\mathrm{B}_{13}$. The configurations for $\mathrm{Al}_{30}$ have the adsorbate located in the 168 beltway of the cluster, labeled $\mathrm{A}_{30}$, or at the caps of the cluster, $\mathrm{B}_{30}$. The $\mathrm{Al}_{32}$ adsorption 169 configurations were based off of the $\mathrm{Al}_{30}$ configurations. In the $\mathrm{A}_{32}$ and $\mathrm{B}_{32}$ configurations, the 170 adsorbates are in the beltway region (which is now partially blocked by the additional Al atoms 171 relative to $\mathrm{Al}_{30}$ ), and in the $\mathrm{C}_{32}$ configuration the adsorbates are above the molecular caps.

172 As previously reported, the $16+$ form of the $\mathrm{Al}_{30}$ molecule was shown to be more stable 173 than the $18+$ form by using vibrational analysis, while several stable $16+$ isomers were 174 found.(Abeysinghe et al., 2013b) Therefore, in modeling adsorption on $\mathrm{Al}_{30}$, we have the 175 additional consideration of which $16+$ isomer(s) to consider. While not exhaustive, we chose 176 two $16+\mathrm{Al}_{30}$ isomers on which to model adsorption, in which two (symmetry-related) $\eta-\mathrm{H}_{2} \mathrm{O}$ 177 groups are deprotonated. In one $\mathrm{Al}_{30}{ }^{16+}$, the deprotonated $\eta-\mathrm{H}_{2} \mathrm{O}$ groups are in the beltway, 178 labeled as "a", and in the other, the deprotonated $\eta-\mathrm{H}_{2} \mathrm{O}$ groups are at the cap sites, labeled as 179 "b", also shown in Figure 1. The difference in the DFT total energy of the two 16+ isomers is $180 \quad 0.86 \mathrm{eV}$.(Casey et al., 2005) Therefore, we consider both deprotonation states as possible starting 181 points for subsequent adsorption. The two deprotonation sites, a and b, and two adsorption 182 configurations, $\mathrm{A}$ and $\mathrm{B}$, results in 4 possible configurations: $\mathrm{A}_{\mathrm{a} 30}, \mathrm{~B}_{\mathrm{b} 30}, \mathrm{~A}_{\mathrm{b} 30}$, and $\mathrm{B}_{\mathrm{a} 30}$. The $\mathrm{A}_{\mathrm{a} 30}$ 183 structure is where the beltway sites are deprotonated to form the $16+$ molecule and OS 184 adsorption is at the beltway, the $\mathrm{B}_{\mathrm{b} 30}$ structure is where the cap sides are deprotonated to form the 
$18516+$ molecule and $\mathrm{OS}$ adsorption is at the caps, the $\mathrm{A}_{\mathrm{b} 30}$ structure is where the cap sites are

186 deprotonated to form the $16+$ molecule and OS adsorption is at the beltway, and the $\mathrm{B}_{\mathrm{a} 30}$

187 structure is where the beltway sites are deprotonated to form the $16+$ molecule and OS

188 adsorption is at the caps.

189 DFT reaction energies, $E_{\mathrm{rxn}}$, are calculated based on Scheme 1 using the total energy

190 information for each reactant and product species, weighted by the appropriate stoichiometric 191 coefficients. In forming $\left(\mathrm{SO}_{4}\right)_{y^{---}} \mathrm{Al}_{\mathrm{x}}$ and $\mathrm{Cl}_{\mathrm{y}^{--}-} \mathrm{Al}_{\mathrm{x}}, \mathrm{Al}_{\mathrm{x}}$ interacts electrostatically with the anion 192 species, where $\mathrm{x}$ equals the number of $\mathrm{Al}$ atoms: $\mathrm{x}=13,30$, and 32 and $\mathrm{y}=1$ or 2 depending on the 193 number of ions adsorbing to the molecule. In order to calculate values of $E_{\mathrm{rxn}}$ by Scheme 1 , the 194 following molecular aqueous species were modeled: $\mathrm{Al}_{13}, \mathrm{Al}_{30}, \mathrm{Al}_{32}, \mathrm{SO}_{4}^{2-}, \mathrm{Cl}^{-}, \mathrm{SO}_{4}^{---} \mathrm{Al}_{13}, \mathrm{Cl}^{---}$

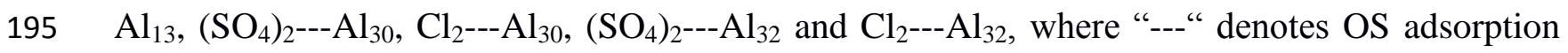
196 between the adsorbing ion(s) and Keggin molecule, and the double adsorption on $\mathrm{Al}_{30}$ and $\mathrm{Al}_{32}$ 197 reflects the molecular inversion symmetry.

\section{Results and Discussion}

Values of $E_{\mathrm{rxn}}$ for sulfate and chloride adsorption configurations are reported in Table 2,

200 with the optimized geometries shown in Figure $2\left(\mathrm{Al}_{13}\right)$, Figure $3\left(\mathrm{Al}_{30}\right)$, and Figure $4\left(\mathrm{Al}_{32}\right)$.

201 The range of $E_{\mathrm{rxn}}$ values for each adsorbate system, $\Delta E_{\mathrm{rxn}}$, is also reported for convenience. For

202 simplicity, we discuss the $\mathrm{A}_{\mathrm{a} 30}$ and $\mathrm{B}_{\mathrm{b} 30}$ results to represent $\mathrm{Al}_{30}$, as they show the greater range 203 in $E_{\mathrm{rxn}}$.

The magnitude of the most favorable values of $E_{\mathrm{rxn}}$ on the $\mathrm{Al}_{30}$ and $\mathrm{Al}_{32}$ molecules is 205 greater than that for adsorption of either ion on the $\mathrm{Al}_{13}$ molecule. This begs the question if the 206 trends are dictated by the overall formal charge on each Keggin species. As previously discussed 207 in the literature, the total formal charge on each $\mathrm{Al}$ nanocluster $(7+, 18+$, and $20+$ respectively 
208 for $\mathrm{Al}_{13}, \mathrm{Al}_{30}$, and $\mathrm{Al}_{32}$ ) does not represent how charge is distributed, motivating the definition of 209 a surface specific charge, $\sigma$, that effectively normalizes the molecular charge per Al: $210 \sigma=\left(\mathrm{Z}+\Sigma_{\max }\right) / \mathrm{Al}_{\text {surf }}$. Here, $\mathrm{Z}$ stands for the average number of protons lost per Al nanocluster, $\Sigma_{\max }$ 211 represents the total charge at the fully protonated state, and $\mathrm{Al}_{\text {surf }}$ is the total number of $\mathrm{Al}$ atoms 212 in each $\mathrm{Al}$ nanocluster.(Casey et al., 2005) Using this definition of $\sigma$ and the $16^{+}$state of $\mathrm{Al}_{30}$ we 213 model here, all three of the Al polycations have $\sigma$ values in the range of 0.53 to 0.66 charge units. 214 Here, we use the DFT results and Mulliken (Mulliken et al., 1949) population analysis to 215 investigate if there are significant variations in the local charges of $\mathrm{Al}$ atoms in the $\mathrm{Al}$ 216 nanoclusters. The Mulliken charges on the $\mathrm{Al}$ atoms are on average $1.51 \mathrm{e}, 1.52 \mathrm{e}$, and $1.53 \mathrm{e}$ for $217 \mathrm{Al}_{13}, \mathrm{Al}_{30}$, and $\mathrm{Al}_{32}$, confirming that the distribution of charge per $\mathrm{Al}$ atom is similar in all of the 218 Al nanoclusters.

219 As no direct bonds are formed in OS adsorption, there is no single adsorbate-cluster 220 distance to characterize the optimized configurations. We report the average distance of the 221 sulfate (sulfur atom) and chloride on the Keggin structures to the tetrahedral $\mathrm{Al}\left(\mathrm{Al}_{\mathrm{tet}}\right)$ center for $222 \mathrm{Al}_{13}, \mathrm{Al}_{30}$, and $\mathrm{Al}_{32}$. For sulfate adsorption the average $\mathrm{S}-\mathrm{Al}_{\text {tet }}$ bond distance is $6.070 \AA$ A, $6.479 \AA$, 223 and $6.390 \AA$ for $\mathrm{Al}_{13}, \mathrm{Al}_{30}$, and $\mathrm{Al}_{32}$ respectively and $6.454 \AA, 5.679 \AA$, and $6.133 \AA$ for chloride 224 adsorption on $\mathrm{Al}_{13}, \mathrm{Al}_{30}$, and $\mathrm{Al}_{32}$ respectively. Since each Keggin contains its own unique shape 225 we cannot make an equal comparison between all three Keggin structures, but note that there is 226 no simple correlation between $E_{\mathrm{rxn}}$ and these distances.

227 We also report an $\mathrm{O}---\mathrm{O}$ distance on the surface of $\mathrm{Al}_{30}$ and $\mathrm{Al}_{32}$ in order to observe how 228 the nanocluster geometry changes in response to adsorption. The O---O distance we measure is 229 circled in Figure 3 and Figure 4. On the bare clusters the O---O interatomic distance is $3.530 \AA$ 230 and $3.456 \AA$ for $\mathrm{Al}_{30}$ and $\mathrm{Al}_{32}$, respectively. For $\mathrm{Al}_{30}$ we observe that when sulfate and chloride 
231 adsorb to the beltway this O---O distance expands. This is due to the fact that the $\mathrm{H}$ atoms on one

232 of the $\mathrm{O}$ atoms wants to hydrogen bond with the adsorbate. For sulfate adsorption the O---O

233 distance expands by $0.244 \AA$ and for chloride adsorption the O---O distance expands by $0.270 \AA$.

234 When the adsorbate is on the cap there is only at most a $0.035 \AA$ elongation of the O---O

235 distance. For chloride adsorption on $\mathrm{Al}_{32}$ both beltway structures $\left(\mathrm{A}_{32}\right.$ and $\left.\mathrm{B}_{32}\right)$ have an

236 elongation of the $\mathrm{O}---\mathrm{O}$ distance but only by $0.017 \AA$ and the cap site, $\mathrm{C}_{32}$ has a contraction of

$2370.015 \AA$. For sulfate adsorption the only structure that has an elongation of this O---O distance is

$238 \mathrm{~A}_{32}$. The $\mathrm{A}_{32}$ structure is where the sulfate is trying to fit into this pocket, the O---O distance

239 expands by $0.056 \AA$. For $\mathrm{B}_{32}$ and $\mathrm{C}_{32}$ the $\mathrm{O}---\mathrm{O}$ bond distance contracts by $0.022 \AA$ and $0.011 \AA$

240 respectively. The analysis of surface O-O separations shows that adsorption can induce

241 significant changes in the cluster geometry, which may contribute to trends and variations in $E_{\mathrm{rxn}}$.

242 Charge population analysis is carried out to further characterize the adsorption

243 configurations, and is reported in Table 3. Charge population analysis is a semi-quantitative

244 approach in which the electron density (obtained from the DFT calculation) within a region is

245 summed, along with the nuclear charge, to yield an atomic partial charge. Atomic partial charges

246 can be summed to determine the charge on a molecule or fragment in a system. On $\mathrm{Al}_{13}$, the

247 sulfate and chloride charge is unchanged between the $\mathrm{A}_{13}$ and $\mathrm{B}_{13}$ configurations. The largest

248 variation in adsorbate charge between configurations is seen for $\mathrm{SO}_{4}{ }^{2-}$ on $\mathrm{Al}_{32}$. In the $\mathrm{B}_{32}$

249 configuration, the charge on $\mathrm{SO}_{4}{ }^{2-}$ has been reduced by $0.65 \mathrm{e}$, while in the $\mathrm{C}_{32}$ configuration the

250 charge has only been reduced by 0.44 e. There are also variations in adsorbate charge in the

251 chloride $\mathrm{Al}_{32}$ configurations and the $\mathrm{Al}_{30} \mathrm{SO}_{4}{ }^{2-}$ and $\mathrm{Al}_{30} \mathrm{Cl}^{-}$configurations. The trend can be

252 summarized as showing that when anions adsorb in beltway configurations on $\mathrm{Al}_{30}$ and $\mathrm{Al}_{32}$, 
253 there is a greater extent of charge transfer with the Al nanocluster, and this trend correlates with 254 the larger magnitude values of $E_{\mathrm{rxn}}$ for beltway configurations.

255 The comparison of $E_{\mathrm{rxn}}$ values on $\mathrm{Al}_{13}, \mathrm{Al}_{30}$, and $\mathrm{Al}_{32}$ nanoclusters and the charge 256 population analysis supports that there is a shape-reactivity relationship governing adsorption 257 behavior on the $\mathrm{Al}$ nanocluster surfaces: On the spherical $\mathrm{Al}_{13}, E_{\mathrm{rxn}}$ varies by at most $0.11 \mathrm{eV}$, 258 while the variation between configurations with adsorbates at the beltway versus cap 259 configurations on $\mathrm{Al}_{30}$ and $\mathrm{Al}_{32}$ is $0.28-1.27 \mathrm{eV}$. The Mulliken population analysis in Table 3 260 shows that the relatively strong adsorption in the beltway configurations is accompanied by a 261 greater extent of charge transfer between the adsorbate and the $\mathrm{Al}$ nanocluster. In order to 262 visualize the interactions between the anions and the Al nanoclusters, we calculate and plot the 263 induced charge density, $\Delta \rho$, taken as $\rho_{\mathrm{SO}_{4} / \mathrm{Al}_{\mathrm{X}}}-\rho_{\mathrm{Al}_{\mathrm{X}}}-\rho_{\mathrm{SO}_{4}}$, where $\rho_{\mathrm{SO}_{4} / \mathrm{Al}_{\mathrm{X}}}$ is the charge 264 density from the sulfate adsorbed cluster, $\rho_{\mathrm{Al}_{\mathrm{x}}}$ is the charge density from the $\mathrm{Al}$ nanocluster, and $265 \rho_{\mathrm{SO}_{4}}$ is the charge density from just the sulfate ions in their same geometry as if there were 266 adsorbed onto the Al nanoclusters. The resulting isosurfaces are shown in Figure 5. Figure 5 267 shows $\Delta \rho$ for the sulfate $\mathrm{B}$ configuration on $\mathrm{Al}_{13}$ as well as the $\mathrm{A}$ and $\mathrm{C}$ configurations for $\mathrm{Al}_{32}$. 268 All of the $\Delta \rho$ plots use the same isosurface value. Comparing the beltway $\left(\mathrm{A}_{32}\right)$ and cap $\left(\mathrm{C}_{32}\right)$ 269 configurations, it is qualitatively apparent that there is a larger volume bound by the isosurfaces 270 for $\mathrm{A}_{32}$. The same can also be seen for beltway adsorption of $\mathrm{SO}_{4}{ }^{2-}$ on $\mathrm{Al}_{30}$, as previously shown 271 in Abeysinghe et al (2013b). Again using a piece of paper as an analogy for how the functional 272 groups are distributed on the $\mathrm{Al}_{32}$ particle surface, the caps are like a flat page, which sterically 273 limits how many functional groups interact with $\mathrm{SO}_{4}{ }^{2-}$ in $\mathrm{C}_{32}$. The beltway corresponds to the 274 inside of a rolled piece of paper, which increases $\mathrm{Al}_{32}-\mathrm{SO}_{4}{ }^{2-}$ interactions in $\mathrm{A}_{32}$. In contrast, the 
275 round shape means that $\mathrm{Al}_{13}-\mathrm{SO}_{4}{ }^{2-}$ interactions are both limited relative to the $\mathrm{Al}_{30}$ and $\mathrm{Al}_{32}$ 276 beltway, and are also uniform throughout the $\mathrm{Al}_{13}$ particle surface.

277 The shape-reactivity relationship supported by the DFT calculations can be represented

278 by considering the $V_{\mathrm{el}}$ as shown in Figure 6 . The electrostatic potential for $\mathrm{Al}_{13}$ is relatively 279 uniform as a function of location on the particle surface while $\mathrm{Al}_{30}$ and $\mathrm{Al}_{32}$ show variation in $280 V_{\mathrm{el}}$, with the most positive values in the beltway and the least positive values at the caps. We 281 interpret the correlation between $V_{\mathrm{el}}$ and $E_{\mathrm{rxn}}$ as evidence that $V_{\mathrm{el}}$ may be useful as a predictor of 282 the relative strength and range of OS adsorption energies on differently shaped Al nanoclusters. 283 However, $V_{\mathrm{el}}$ is not the only factor governing reactivity, as steric effects can also influence 284 adsorption trends. For example, while both $\mathrm{Al}_{30}$ and $\mathrm{Al}_{32}$ exhibit more positive regions of $V_{\mathrm{el}}$ in 285 the molecular beltway, the beltway surface of $\mathrm{Al}_{32}$ is less accessible due to the additional $\mathrm{Al}$ 286 atoms in the structure.

\section{Conclusion}

The DFT modeling of OS adsorption of $\mathrm{SO}_{4}{ }^{2-}$ and $\mathrm{Cl}^{-}$on the surfaces of $\mathrm{Al}_{13}, \mathrm{Al}_{30}$, and $289 \mathrm{Al}_{32}$ supports the existence of a shape-reactivity relationship in $\mathrm{Al}$ nanoclusters. Combined with 290 our previous adsorption modeling, we conclude that the shape-reactivity relationship affects both 291 IS and OS adsorption, but particularly gives rise to unusually strong OS anion adsorption in the 292 beltway of the larger Al Keggin nanoclusters. There are implications of these results for the use 293 of Al Keggin nanostructures in precipitation-based water treatment. Once a contaminant has 294 been bound by the sorbing Al nanocluster, precipitation of the aluminum polycation complex 295 requires counterions. The results here demonstrate that $\mathrm{SO}_{4}{ }^{2-}$ and $\mathrm{Cl}^{-}$counterions interact more 296 strongly with $\mathrm{Al}_{30}$ and $\mathrm{Al}_{32}$ (the Keggins that exhibit gradients in $V_{\mathrm{el}}$ due to their shape) relative 297 to $\mathrm{Al}_{13}$. This suggests that shape and gradients in $V_{\mathrm{el}}$ should be considered in optimizing the 
298 performance of $\mathrm{Al}$ sorbents to be used in precipitation-based water remediation. The shape299 reactivity relationship may be of particular use in comparing adsorption trends on nanocluster 300 sorbents of the same composition, but varying shape and size. The need for sustainable water 301 remediation strategies is a driving force for ongoing efforts to fundamentally understand 302 nanocluster reactivity and adsorption processes.

\section{Acknowledgements}

304 This work was supported by NSF grant CHE-1254127, and utilized computational resources 305 provided by the University of Iowa College of Liberal Arts and Sciences. 


\section{References}

Abadia, M., Gonzalez-Moreno, R., Sarasola, A., Otero-Irurueta, G., Verdini, A., Floreano, L., Garcia-Lekue, A. and Rogero, C., 2014. Massive surface reshaping mediated by metalorganic complexes. J. Phys. Chem. C 118(51), 29704-29712.

Abeysinghe, S., Corum, K.W., Neff, D.L., Mason, S.E. and Forbes, T.Z., 2013b. Contaminant adsorption on nanoscale particles: structural and theoretical characterization of $\mathrm{Cu}^{2+}$ bonding on the surface of Keggin-type polyaluminum $\left(\mathrm{Al}_{30}\right)$ molecular species. Langmuir 29(46), 14124-14134.

Abeysinghe, S., Unruh, D.K. and Forbes, T.Z., 2012. Crystallization of Keggin-type polyaluminum species by supramolecular interactions with disulfonate anions. Cryst. Growth Des. 12(4), 2044-2051.

Abeysinghe, S., Unruh, D.K. and Forbes, T.Z., 2013. Surface modification of $\mathrm{Al}_{30}$ Keggin-type polyaluminum molecular clusters. Inorg. Chem. 52(10), 5991-5999.

Brown, G.E. and Calas, G., 2011. Environmental mineralogy - understanding element behavior in ecosystems. C. R. Geosci. 343(2-3), 90-112.

Brown, I.D., 2009. Recent developments in the methods and applications of the bond valence model. Chem. Rev. 109(12), 6858-6919.

Casey, W.H., 2006. Large aqueous aluminum hydroxide molecules. Chem. Rev. 106(1), 1-16.

Casey, W.H. and Rustad, J.R., 2007. Reaction dynamics, molecular clusters, and aqueous geochemistry. Annu. Rev. Earth. Pl. Sc. 35, 21-46.

Casey, W.H., Rustad, J.R., Banerjee, D. and Furrer, G., 2005. Large molecules as models for small particles in aqueous geochemistry research. J. Nanoparticle Res. 7(4-5), 377-387.

Catalano, J.G., 2010. Relaxations and interfacial water ordering at the corundum (110) surface. J. Phys. Chem. C 114(14), 6624-6630.

Catalano, J.G., Park, C., Fenter, P. and Zhang, Z., 2008. Simultaneous inner- and outer-sphere arsenate adsorption on corundum and hematite. Geochim. Cosmochim. Ac. 72(8), 19862004.

Corum, K.W. and Mason, S.E., 2015. Establishing trends in ion adsorption on the aqueous aluminium hydroxide nanoparticle $\mathrm{Al}_{30}$. Mol. Simulat. 41(1-3), 146-155.

Delley, B., 1990. An all-electron numerical-method for solving the local density functional for polyatomic-molecules. J. Chem. Phys. 92(1), 508-517.

Delley, B., 2000. From molecules to solids with the DMol ${ }^{3}$ approach. J. Chem. Phys. 113(18), 7756-7764.

Eng, P.J., Trainor, T.P., Brown, G.E., Waychunas, G.A., Newville, M., Sutton, S.R. and Rivers, M.L., 2000. Structure of the hydrated $\alpha-\mathrm{Al}_{2} \mathrm{O}_{3}$ (0001) surface. Science 288(5468), 10291033.

Fairley, M., Corum, K.W., Johns, A., Unruh, D.K., Basile, M., de Groot, J., Mason, S.E. and Forbes, T.Z., 2015. Isolation and characterization of the $\left[\mathrm{Ga}_{2} \mathrm{Al}_{18} \mathrm{O}_{8}(\mathrm{OH})_{36}\left(\mathrm{H}_{2} \mathrm{O}\right)_{12}\right]^{8+}$ cluster: cationic variations on the Wells-Dawson topology. Chem. Comm. 51(62), $12467-$ 12469.

Fenter, P., Cheng, L., Rihs, S., Machesky, M., Bedzyk, M.J. and Sturchio, N.C., 2000. Electrical double-layer structure at the rutile-water interface as observed in situ with small-period Xray standing waves. J. Colloid Interface Sci. 225(1), 154-165.

Fenter, P. and Sturchio, N.C., 2004. Mineral-water interfacial structures revealed by synchrotron X-ray scattering. Prog. Surf. Sci. 77(5-8), 171-258. 
Furrer, G., Phillips, B.L., Ulrich, K.U., Pothig, R. and Casey, W.H., 2002. The origin of aluminum flocs in polluted streams. Science 297(5590), 2245-2247.

Hiemstra, T., Vanriemsdijk, W.H. and Bolt, G.H., 1989. Multisite proton adsorption modeling at the solid-solution interface of (hydr)oxides - a new approach .1. model description and evaluation of intrinsic reaction constants. J. Colloid Interface Sci. 133(1), 91-104.

Hoover, W.G., 1985. Canonical dynamics - equilibrium phase-space distributions. Phys. Rev. A 31(3), 1695-1697.

Hou, Y., Zakharov, L.N. and Nyman, M., 2013. Observing assembly of complex inorganic materials from polyoxometalate building blocks. J. Am. Chem. Soc. 135(44), 16651-16657.

Israelachvili, J.N. and Adams, G.E., 1978. Measurement of forces between 2 mica surfaces in aqueous-electrolyte solutions in range 0-100nm. J. Chem. Soc. Farady Trans. 74(4), 9751001.

Johansson, G., 1960. On the crystal structures of some basic aluminium salts. Acta Chem. Scand. 14(3), 771-773.

Jordan, D.S. and Geiger, F. M., 2014. Interaction of aluminum ions with fused silica/water interfaces in the presence of oxalic acid tracked by second harmonic generation. J. Phys. Chem. C. 118(50), 28970-28977.

Klamt, A. and Schüürmann, G., 1993. Cosmo - a new approach to dielectric screening in solvents with explicit expressions for the screening energy and its gradient. J. Chem. Soc. Perk. T. 2 (5), 799-805.

Leung, K., Rempe, S.B., and Lorenz, C.D, 2006. Salt permeation and exclusion in hydroxylated and functionalized silica pores. Phys. Rev. Let. 96(9), 095504-1-095504-4.

Mertens, J., 2011. Al nanoclusters in coagulants and granulates: application in arsenic removal from water. Rev. Emviron. Sci. Biotechnol. 10(2), 111-117.

Mertens, J., Casentini, B., Masion, A., Pothig, R., Wehrli, B. and Furrer, G., 2012. Polyaluminum chloride with high $\mathrm{Al}_{30}$ content as removal agent for arsenic-contaminated well water. Water Res. 46(1), 53-62.

Mertens, J., Rose, J., Kagi, R., Chaurand, P., Plotze, M., Wehrli, B. and Furrer, G., 2012b. Adsorption of arsenic on polyaluminum granulate. Environ. Sci. Technol. 46(13), 73107317.

Mertens, J., Rose, J., Wehrli, B. and Furrer, G., 2016. Arsenate uptake by Al nanoclusters and other Al-based sorbents during water treatment. Water Res. 88, 844-851.

Michel, F.M., Barron, V., Torrent, J., Morales, M.P., Serna, C.J., Boily, J.F., Liu, Q.S., Ambrosini, A., Cismasu, A.C. and Brown, G.E., 2010. Ordered ferrimagnetic form of ferrihydrite reveals links among structure, composition, and magnetism. P Natl. Acad. Sci. USA 107(7), 2787-2792.

Mulliken, R.S., Rieke, C.A., Orloff, D. and Orloff, H., 1949. Formulas and numerical tables for overlap integrals. J. Chem. Phys. 17(12), 1248-1267.

Nose, S., 1984. A unified formulation of the constant temperature molecular-dynamics methods. J. Chem. Phys. 81(1), 511-519.

Pauling, L., 1929. The principles determining the structure of complex ionic crystals. J. Am. Chem. Soc. 51, 1010-1026.

Perdew, J.P., Burke, K. and Ernzerhof, M., 1996. Generalized gradient approximation made simple. Phys. Rev. Lett. 77(18), 3865-3868.

Reusser, D., Casey, W.H. and Navrotsky, A., 2014. Energetics of heterometal substitution in epsilon-Keggin $\left[\mathrm{MO}_{4} \mathrm{Al}_{12}(\mathrm{OH})_{24}\left(\mathrm{OH}_{2}\right)_{12}\right]^{6 / 7 / 8+}$ ions. Am. Mineral. 99(11-12), 2337-2343. 
Rosso, K.M., Yanina, S.V., Gorski, C.A., Larese-Casanova, P. and Scherer, M.M., 2010. Connecting observations of hematite $\left(\alpha-\mathrm{Fe}_{2} \mathrm{O}_{3}\right)$ growth catalyzed by $\mathrm{Fe}(\mathrm{II})$. Environ. Sci. Technol. 44(1), 61-67.

Rustad, J.R., 2005. Molecular dynamics simulation of the titration of polyoxocations in aqueous solution. Geochim. Cosmochim. Ac. 69(18), 4397-4410.

Rustad, J.R. and Casey, W.H., 2012. Metastable structures and isotope exchange reactions in polyoxometalate ions provide a molecular view of oxide dissolution. Nat. Mater. 11(3), 223226.

Rustad, J.R., Loring, J.S. and Casey, W.H., 2004. Oxygen-exchange pathways in aluminum polyoxocations. Geochim. Cosmochim. Ac. 68(14), 3011-3017.

Sadeghi, O., Zakharov, L.N. and Nyman, M., 2015. Aqueous formation and manipulation of the iron-oxo Keggin ion. Science 347(6228), 1359-1362.

Sun, Z., Wang, H., Tong, H.G. and Sun, S.F., 2011. A giant polyaluminum species S- $\mathrm{Al}_{32}$ and two aluminum polyoxocations involving coordination by sulfate ions $\mathrm{S}-\mathrm{Al}_{32}$ and $\mathrm{S}-\mathrm{K}-\mathrm{Al}_{13}$. Inorg. Chem. 50(2), 559-564. 


\section{Schemes}

$$
\begin{gathered}
\frac{1}{y}\left[\mathrm{Al}_{\mathrm{x}}+\mathrm{y} \mathrm{SO}_{4}{ }^{2-} \rightarrow\left(\mathrm{SO}_{4}\right)_{\mathrm{y}}-\mathrm{Al}_{\mathrm{x}}\right] \\
\frac{1}{y}\left[\mathrm{Al}_{\mathrm{x}}+\mathrm{y} \mathrm{Cl} \mathrm{Cl}^{-} \rightarrow \mathrm{Cl}_{\mathrm{y}}-\mathrm{Al}_{\mathrm{x}}\right]
\end{gathered}
$$

415

416 Scheme 1. Model reactions for the outer-sphere adsorption of $\mathrm{SO}_{4}{ }^{2-}$ and $\mathrm{Cl}^{-}$, where $\mathrm{x}$ stands for 417 the number of $\mathrm{Al}$ atoms in the nanoparticle $\left(13,30\right.$, or 32) and $\mathrm{y}$ stands for the number of $\mathrm{SO}_{4}{ }^{2-}$ 418 or $\mathrm{Cl}^{-}$ions. There are $2 \mathrm{SO}_{4}{ }^{2-}$ and $\mathrm{Cl}^{-}$ions for $\mathrm{Al}_{30}$ and $\mathrm{Al}_{32}$ due to the inversion symmetry of the 419 nanocluster and one $\mathrm{SO}_{4}{ }^{2-}$ and $\mathrm{Cl}^{-}$ion per $\mathrm{Al}_{13}$. 


\section{Figure Captions}

424 Figure 1. The initial outer-sphere adsorption configurations for $\mathrm{SO}_{4}{ }^{2-}$ and $\mathrm{Cl}^{-}$on $\mathrm{Al}_{13}, \mathrm{Al}_{30}$, and

425

426

427

428

429

430

431

432

433

434

435

436

437

438

439

440

441

442

443

444

445

446

447

448

449

450

451

452

453

454

455

456

457

458

459

460

461

462
Figure 2. DFT geometry optimized structures of $\mathrm{SO}_{4}---\mathrm{Al}_{13}$ and $\mathrm{Cl}---\mathrm{Al}_{13}$. Aluminum, oxygen, hydrogen, sulfur, and chlorine are shown by blue, red, gray, orange, and green spheres, respectively. From left to right: $\mathrm{SO}_{4}---\mathrm{A}_{13}, \mathrm{SO}_{4}^{---} \mathrm{B}_{13}, \mathrm{Cl}---\mathrm{A}_{13}$, and $\mathrm{Cl}---\mathrm{B}_{13}$.

Figure 3. DFT geometry optimized structures of $\left(\mathrm{SO}_{4}\right)_{2}{ }^{---} \mathrm{Al}_{30}$ and $\mathrm{Cl}_{2}---\mathrm{Al}_{30}$. Aluminum, oxygen, hydrogen, sulfur, and chlorine are shown by blue, red, gray, orange, and green spheres, respectively. From left to right: $\left(\mathrm{SO}_{4}\right)_{2^{---}} \mathrm{A}_{\mathrm{a} 30},\left(\mathrm{SO}_{4}\right)_{2^{--}}-\mathrm{B}_{\mathrm{b} 30}, \mathrm{Cl}_{2^{---}} \mathrm{A}_{\mathrm{a} 30}$, and $\mathrm{Cl}_{2^{---}} \mathrm{B}_{\mathrm{b} 30}$. The black circle around the two oxygen atoms on the left most structure show which oxygen atoms are used to monitor an O---O interatomic distance before and after adsorption.

Figure 4. DFT geometry optimized structures of $\left(\mathrm{SO}_{4}\right)_{2}---\mathrm{Al}_{32}$ and $\mathrm{Cl}_{2}---\mathrm{Al}_{32}$. Aluminum, oxygen, hydrogen, sulfur, and chlorine are shown by blue, red, gray, orange, and green spheres, respectively. From left to right and top to bottom: $\left(\mathrm{SO}_{4}\right)_{2}{ }^{---} \mathrm{A}_{32},\left(\mathrm{SO}_{4}\right)_{2}{ }^{---} \mathrm{B}_{32},\left(\mathrm{SO}_{4}\right)_{2}---\mathrm{C}_{32}, \mathrm{Cl}_{2^{---}}$ $\mathrm{A}_{32}$, and $\mathrm{Cl}_{2---} \mathrm{B}_{32}, \mathrm{Cl}_{2^{---}} \mathrm{C}_{32}$. The black circle around the two oxygen atoms on the left most structure show which $\mathrm{O}$ atoms are used to monitor an $\mathrm{O}---\mathrm{O}$ interatomic distance before and after adsorption.

Figure 5. From left to right induced charge density $\Delta \rho$ for sulfate adsorption for the $\mathrm{B}_{13}, \mathrm{~A}_{32}$, and $\mathrm{C}_{32}$ configurations. Adsorption causes electron flow from the regions bound by black isosurfaces to regions bound by yellow isosurfaces. The same isosurface value is used in all of the figures, thus the relative volume bound by the isosurfaces in each structure correlates to the relative amount of charge transfer between the adsorbate and Keggin molecule. 
463 Figure 6. Plots of $V_{\mathrm{el}}$ mapped onto charge density isosurfaces of $\mathrm{Al}_{13}, \mathrm{Al}_{30}$, and $\mathrm{Al}_{32}$. The 464 electrostatic potential is positive throughout, with higher positive values shown in red and lower 465 positive values shown in blue.For all three, the same scale is used and all three have a range of $46616 \mathrm{eV} / e$. The relative lack of gradient in the $V_{\mathrm{el}}$ of the $\mathrm{A}_{13}$ molecule compared to $\mathrm{Al}_{30}$ and $\mathrm{Al}_{32}$ 467 correlates with the relatively small range in $E_{\mathrm{rxn}}$ for the former. 
471 Table 1. Average tetrahedral bond length (in $\AA$ ) comparison between the DFT optimized

472 nanoparticles and the experimental crystal structures.

473

\begin{tabular}{|c|c|c|c|}
\hline Bond Lengths $(\AA)$ & $\mathrm{Al}_{13}$ & $\mathrm{Al}_{30}$ & $\mathrm{Al}_{32}$ \\
\hline DFT & 1.815 & 1.824 & 1.824 \\
\hline Experimental & $1.838^{\mathrm{a}}$ & $1.797^{\mathrm{b}}$ & $1.805^{\mathrm{c}}$ \\
\hline
\end{tabular}

474 b.(Abeysinghe et al., 2012)

475 c.(Abeysinghe et al., 2013a)

476

477

478

479

480

Table 2. Calculated values of $E_{\mathrm{rxn}}\left(\mathrm{in} \mathrm{eV}\right.$ ) for sulfate and chloride adsorption on $\mathrm{Al}_{13}, \mathrm{Al}_{30}$, and $\mathrm{Al}_{32}$. In the two rows for $\mathrm{Al}_{30} \mathrm{~A}_{\mathrm{a}}$ and $\mathrm{B}_{\mathrm{b}}$ represents that adsorption and deprotonation are occurring in the same location while $\mathrm{A}_{\mathrm{b}}$ and $\mathrm{B}_{\mathrm{a}}$ represents that adsorption and deprotonation are occurring in mismatched locations, as described in the text.

\begin{tabular}{|c|c|c|c|c|}
\hline$E_{\mathrm{rxn}}(\mathrm{eV})$ & A & B & $\mathrm{C}$ & $\Delta_{\max }$ \\
\hline $\mathrm{SO}_{4---\mathrm{Al}_{13}}$ & -1.76 & -1.87 & & $|0.11|$ \\
\hline 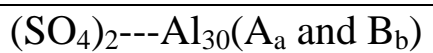 & -2.34 & -1.39 & & $\mid 0.95$ \\
\hline$\left(\mathrm{SO}_{4}\right)_{2^{--}} \mathrm{Al}_{30}\left(\mathrm{~A}_{\mathrm{b}}\right.$ and $\left.\mathrm{B}_{\mathrm{a}}\right)$ & -2.84 & -1.96 & & $|0.88|$ \\
\hline$\left(\mathrm{SO}_{4}\right)_{2}---\mathrm{Al}_{32}$ & -2.89 & -2.44 & -1.63 & 1.27 \\
\hline Cl---Al $\mathrm{Al}_{13}$ & -1.18 & -1.30 & & $|0.12|$ \\
\hline 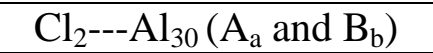 & -1.85 & -0.99 & & $\mid 0.86$ \\
\hline $\mathrm{Cl}_{2^{--}-\mathrm{Al}_{30}\left(\mathrm{~A}_{\mathrm{b}} \text { and } \mathrm{B}_{\mathrm{a}}\right)}$ & -1.62 & -1.34 & & $|0.28|$ \\
\hline $\mathrm{Cl}_{2^{--}-\mathrm{Al}_{32}}$ & -1.95 & -1.60 & -1.14 & $\mid 0.81$ \\
\hline
\end{tabular}

Table 3. Mulliken population analysis values for the sulfate and chloride ions in the DFT geometry optimized configurations. In the two rows for $\mathrm{Al}_{30} \mathrm{~A}_{\mathrm{a}}$ and $\mathrm{B}_{\mathrm{b}}$ represents that adsorption and deprotonation are occurring in the same location while $A_{b}$ and $B_{a}$ represents that adsorption and deprotonation are occurring in mismatched locations, as described in the text.

\begin{tabular}{|c|c|c|c|c|}
\hline Mulliken Values (e) & A & B & $\mathrm{C}$ & $\Delta_{\max }$ \\
\hline $\mathrm{SO}_{4---} \mathrm{Al}_{13}$ & -1.53 & -1.53 & & $|0.00|$ \\
\hline$\left(\mathrm{SO}_{4}\right)_{2---} \mathrm{Al}_{30}\left(\mathrm{~A}_{\mathrm{a}}\right.$ and $\left.\mathrm{B}_{\mathrm{b}}\right)$ & -1.50 & -1.57 & & $|0.07|$ \\
\hline 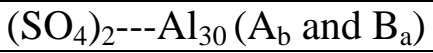 & -1.40 & -1.54 & & $|0.14|$ \\
\hline$\left(\mathrm{SO}_{4}\right)_{2}---\mathrm{Al}_{32}$ & -1.45 & -1.35 & -1.56 & $|0.21|$ \\
\hline $\mathrm{Cl}---\mathrm{Al}_{13}$ & -0.65 & -0.65 & & $|0.00|$ \\
\hline 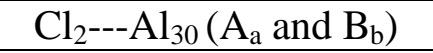 & -0.61 & -0.74 & & $\mid 0.13$ \\
\hline 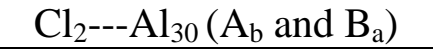 & -0.60 & -0.67 & & |0.07| \\
\hline $\mathrm{Cl}_{2^{--}-\mathrm{Al}_{32}}$ & -0.59 & -0.58 & -0.66 & $|0.08|$ \\
\hline
\end{tabular}




\section{FIGURES}

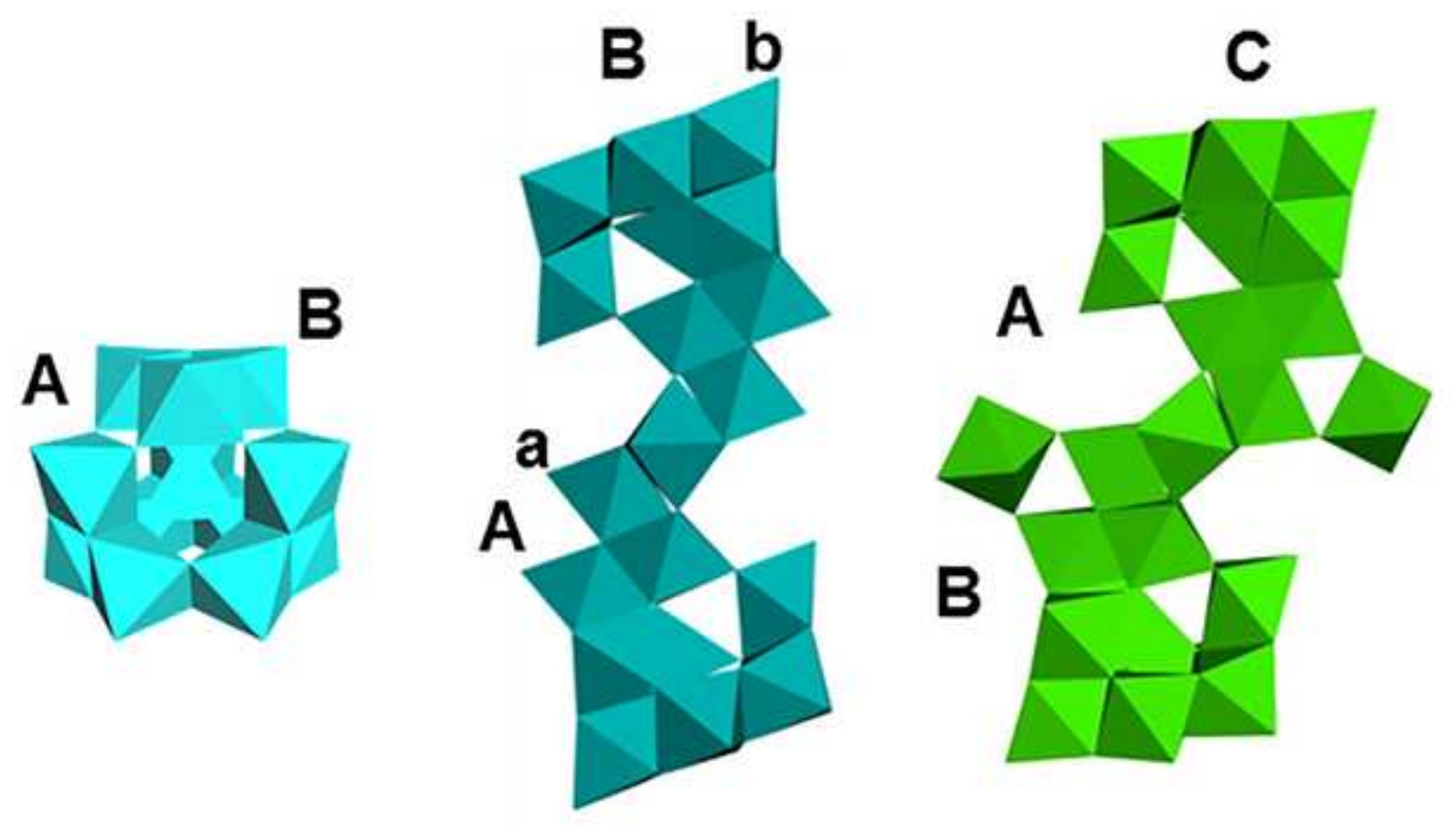



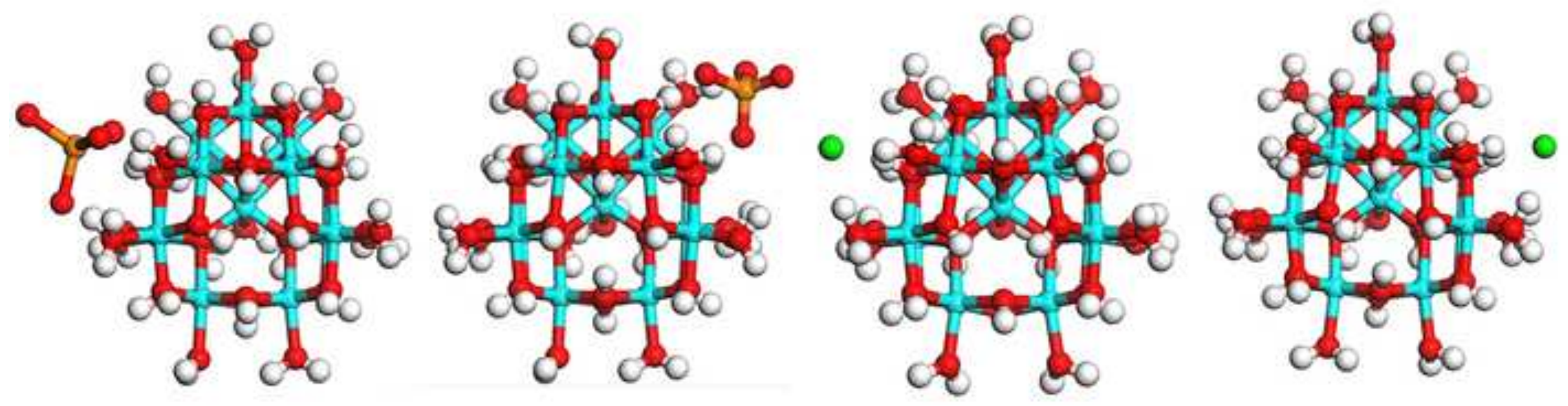

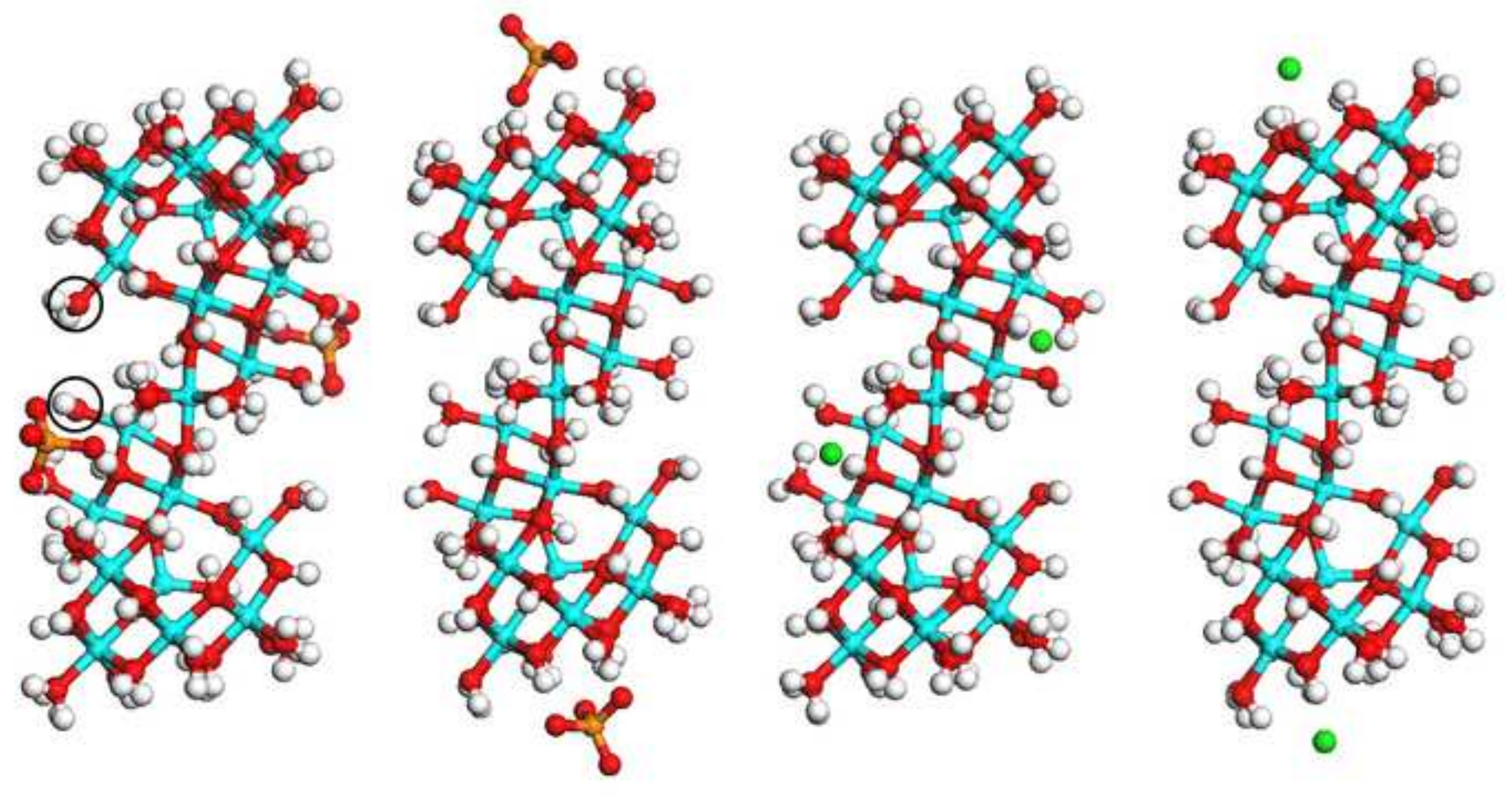

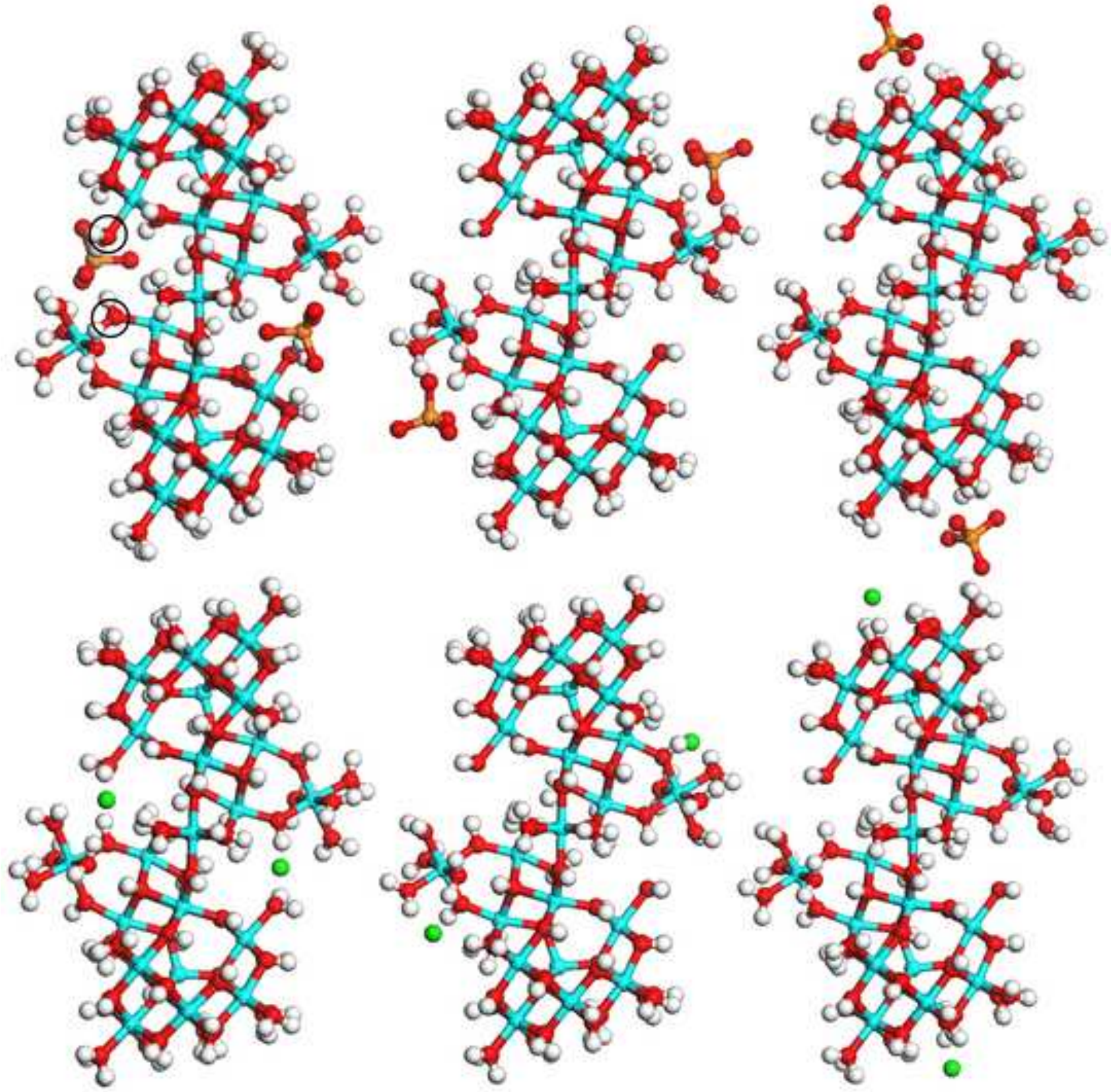


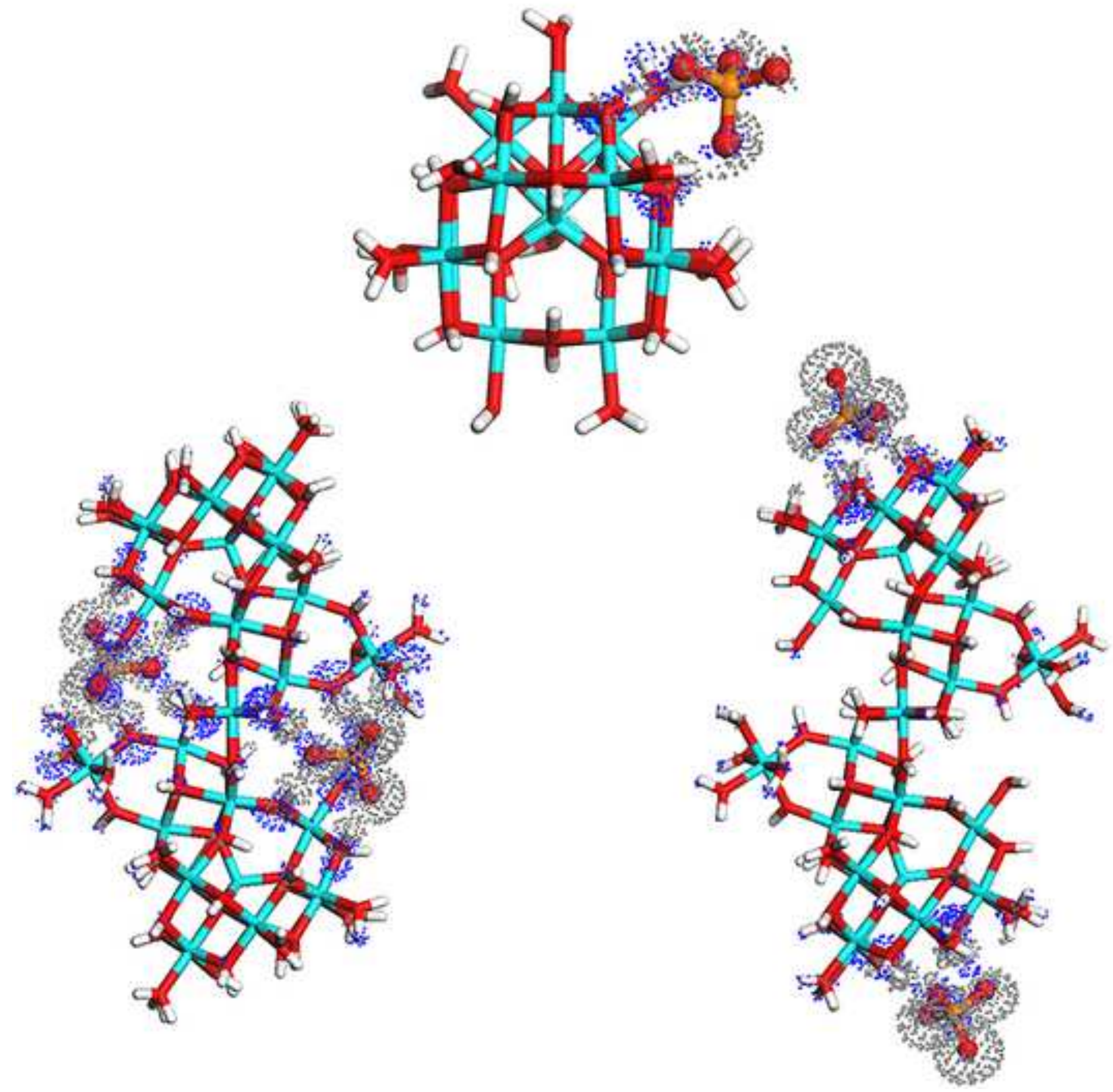

Fiqure 5 

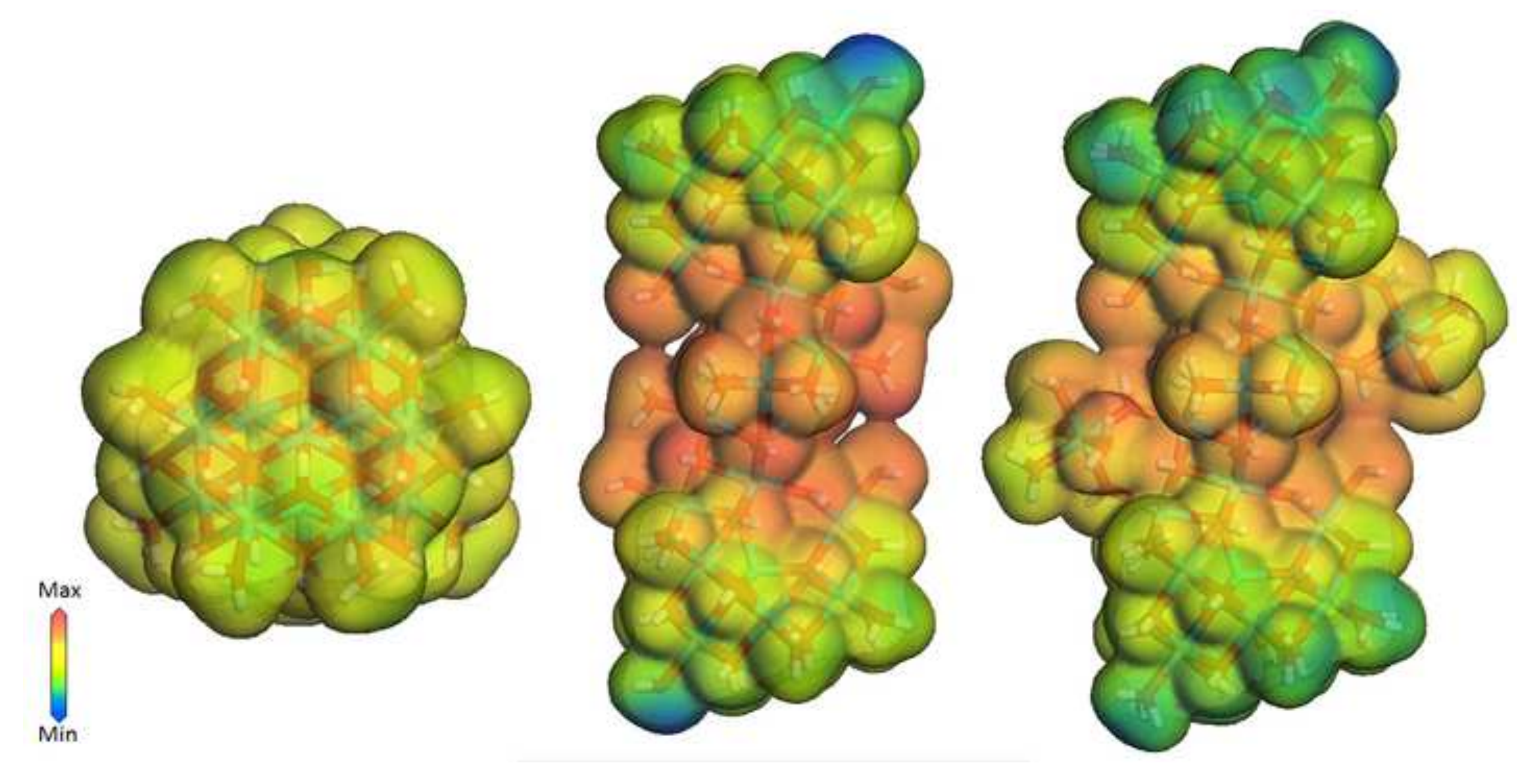

Figure $\epsilon$

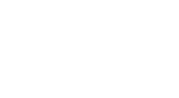


Nanocluster

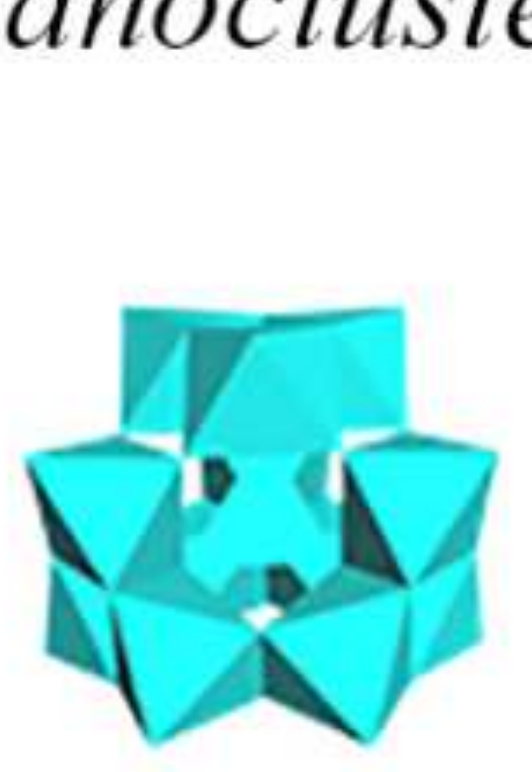

Shape
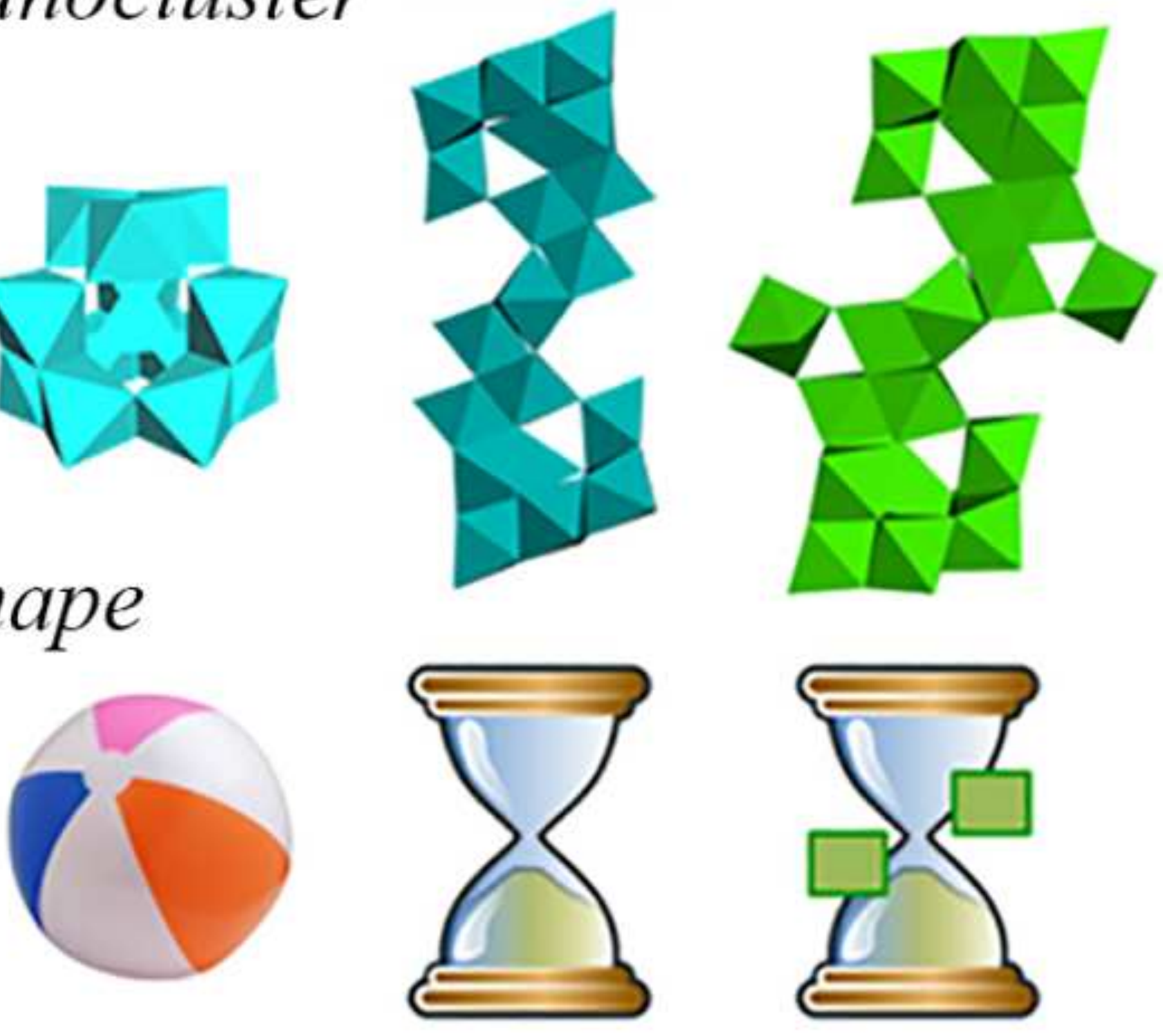